\title{
Evaluation of the effectiveness of sodium hyaluronate, sesame oil, honey, and silver nanoparticles in preventing postoperative surgical adhesion formation. An experimental study ${ }^{1}$
}

Hamid Reza Khorshidi', Amir Kasraianfard", Amir Derakhshanfar"l', Siavash Rahimi'v, Ali Sharifiv, Hamid Reza Makarchian", Manoochehr Ghorbanpoor ${ }^{\mathrm{VII}}$, Seyed Mohammad Reza Javadiv

'Assistant Professor, Department of Surgery, Medical Sciences, Hamadan University, Iran. Scientific and intellectual content of the study, Conception and design of the study, critical revision.

"MD, Resident, Department of Surgery, Medical Sciences, Hamadan University, Iran. Technical procedures, manuscript writing.

I'Associate Professor, Department of Surgery, Medical Sciences, Hamadan University, Iran. Conception and design of the study, critical revision.

IVMD degree, Faculty of Medicine, Medical Sciences, Mazandaran University, Sari, Iran. Acquisition of data, manuscript preparation.

${ }^{\vee}$ Assistant Professor, Department of Surgery, Medical Sciences, Hamadan University, Iran. Critical revision, final approval. ${ }^{V 1}$ Assistant Professor, Department of Surgery, Medical Sciences, Hamadan University, Iran. Statistics analysis, manuscript preparation.

VIIAssistant Professor, Department of Surgery, Medical Sciences, Hamadan University, Iran. Analysis and interpretation of data, technical procedures.

\begin{abstract}
Purpose: To evaluate the effectiveness of sodium hyaluronate, sesame oil, honey, and silver nanoparticles in preventing of postoperative surgical adhesion formation.

Methods: Forty male Wistar rats were randomly assigned into five groups with eight rats in each group including control, hyaluronate, sesame, honey and silver groups. After two weeks the animals underwent laparotomy and were evaluated by two different blinded surgeons for severity of adhesions based on the two different classification scoring systems including Nair classification and cumulative adhesion scoring scale.

Results: The scores of severity of adhesions in the hyaluronate and sesame groups were significantly lower than the control group based on the Nair classification (both P-values = 0.02), however based on the cumulative adhesion scoring scale just the score of severity of adhesions in the hyaluronate group was significantly lower than the control group ( $P$-value = 0.02 ). In the hyaluronate group the severity of adhesions was decreased by $48 \%$ based on the cumulative adhesion scoring scale.

Conclusions: Sodium hyaluronate and sesame oil may have a significant effect in preventing postoperative surgical adhesion formation.
\end{abstract}

Key words: Hyaluronic Acid. Sesame Oil. Tissue Adhesions. Honey. Nanoparticles. Rats. 


\section{Introduction}

Postoperative surgical adhesion is a common consequence of intraperitoneal surgery which may lead to several complications such as adhesive small bowel obstructions, chronic abdominopelvic pain, and female infertility making a significant adverse impact on health care costs ${ }^{1-3}$.

Many efforts have been made aiming to decrease the rate of postoperative surgical adhesion formation by using anti-inflammatory agents ${ }^{4}$ fibrinolytics ${ }^{5}$, anti-coagulants ${ }^{6}$, mechanical barriers ${ }^{7}$ and anti-biotics ${ }^{8}$. Recently, the anti-inflammatory effect of components of sesame oil has been investigated ${ }^{9,10}$, although the effect on postoperative surgical adhesion formation has not yet been investigated. Hyaluronic acid which naturally coats serosal surfaces and provides a certain degree of protection from serosal desiccation may work as a mechanical barrier for adhesion formation ${ }^{11}$. Silver nanoparticles with antibacterial properties has also been reported to be effective on postoperative surgical adhesion formation $^{12,13}$. Recently, honey -with a long history in medicine- has been suggested to have has anti-inflammatory, wound healing and anti-bacterial properties ${ }^{14,15}$

We conducted the present experimental study aiming to evaluate the effectiveness of sodium hyaluronate, sesame oil, honey, and silver nanoparticles in prevention of postoperative surgical adhesion formation.

\section{Methods}

We conducted this experimental study after obtaining the approval of the Ethics committee of Medical Sciences, Hamadan University from 2015 to 2016.

Forty male albino Wister rats were studied with weight range of 200 - 220 grams.
They were housed in $21^{\circ} \mathrm{C}$ temperature and $60 \%$ \pm 5 humidity and were kept for two weeks under above-mentioned condition for acclamation. Rat pellet and water was accessible ad libitum. Animals were randomly assigned into 5 groups with 8 rats in each group including control, hyaluronate, sesame, honey and silver groups.

All were anesthetized with ketamine 80 $\mathrm{mg} / \mathrm{kg}$ and xylazine $10 \mathrm{mg} / \mathrm{kg}$ subcutaneously without use of antibiotic. Anterior abdominal wall was shaved and disinfected. A three $\mathrm{cm}$ incision was made and after mobilization of cecum and placing it on a wet gauze the cecum was scraped with a sterilized nylon toothbrush in one $\mathrm{cm} \times$ one $\mathrm{cm}$ dimensions till the petechie was seen. Then, one $\mathrm{mL}$ of saline in the control group, one $\mathrm{mL}$ of $10 \%$ sodium hyaluronate solution in the hyaluronate group, one $\mathrm{mL}$ of sesame oil in the sesame group, one $\mathrm{mL}$ of undiluted and purely natural honey which was produced in Hamadan province in the honey group, and $100 \mathrm{ppm}$ of silver with size range of $60-100 \mathrm{~nm}$ in the silver nanoparticles group were instilled on cecum.

After two weeks the animals were euthanized with diethyl ether, underwent laparotomy and were evaluated by two different blinded surgeons for severity of adhesions based on the two different classification scoring systems including Nair classification and cumulative adhesion scoring scale. Nair classification is defined as score zero for complete absence of adhesions, score one for single band of adhesion between viscera, or from vicera to abdominal wall, score two for two bands, either between viscera or from viscera to abdominal wall, score three for more than two bands between viscera or viscera to abdominal wall or whole intestines forming a mass without being adherent to abdominal wall, score four for viscera directly adherent to abdominal wall, irrespective of number and extent of adhesive bands. Cumulative 
adhesion scoring scale is defined as point zero for no adhesion and one point for each of the followings: one adhesion band from the omentum to the target organ, one adhesion band from the omentum to the abdominal scar, one adhesion band from the omentum to another place, one adhesion band from the adnexa/epididymal fat bodies to the target organ, one adhesion band from the adnexa/ epididymal fat bodies to the abdominal scar, one adhesion band from the adnexa/ epididymal fat bodies to another place, any adhesive band other than described above, target organ adherent to the abdominal wall, target organ adherent to the abdominal scar, target organ adherent to the bowel, target organ adherent to the liver or the spleen, any other organ adherent. The final score is the accumulation of the points.

Statistical analyses were performed by using SPSS software (IBM SPSS Statistics for Windows, Version 20.0, IBM Corp., Armonk, NY, USA). Quantitative and qualitative data were analyzed using the Kruskal-Wallis and Mann-Whitney $U$ test, respectively. Statistical significance was defined by $P<0.05$.

\section{Results}

The frequency of scores of severity of adhesions in each group based on the Nair classification is shown in Figure 1. As shown in Table 1, the scores of severity of adhesions in the hyaluronate and sesame groups were significantly lower than the control group based on the Nair classification, however based on the cumulative adhesion scoring scale just the score of severity of adhesions in the hyaluronate group was significantly lower than the control group. In the hyaluronate group the severity of adhesions was decreased by $48 \%$ based on the cumulative adhesion scoring scale. The scores of severity of adhesions in each group based on the cumulative adhesion scoring scale are box-plotted in Figure 2.

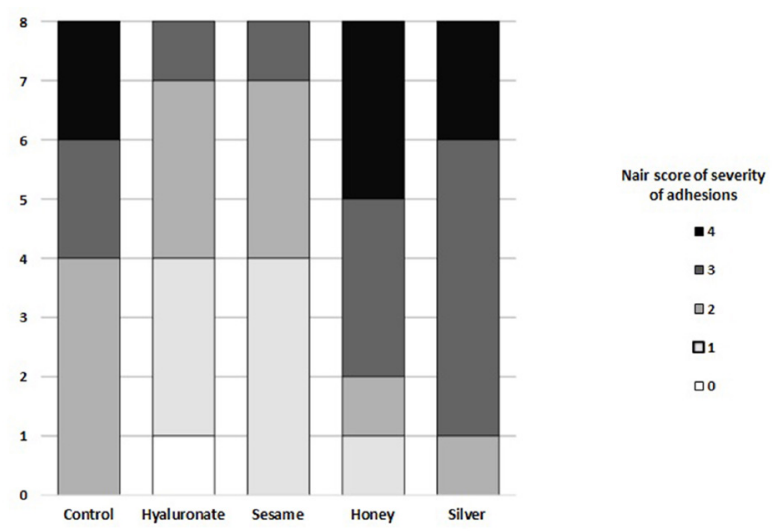

Figure 1 - The frequency of scores of severity of adhesions in each group based on the Nair classification.

Table 1 - The scores of severity of adhesions in each group based on the Nair classification and cumulative adhesion scoring scale.

\begin{tabular}{lllll} 
& Nair classification & P-value* & Cumulative adhesion scoring scale & P-value \\
\hline Control & $2.5 \pm 0.886$ & & $5.5 \pm 2.6$ & \\
Hyaluronate & $1.5 \pm 0.926$ & $\mathbf{0 . 0 2}$ & $3 \pm 1.38$ & $\mathbf{0 . 0 2}$ \\
Sesame & $1.5 \pm 0.744$ & $\mathbf{0 . 0 2}$ & $3 \pm 1.18$ & 0.07 \\
Honey & $3 \pm 1.069$ & 0.5 & $6.5 \pm 2.33$ & 0.49 \\
Silver & $3 \pm 0.641$ & 0.3 & $6.5 \pm 2.56$ & 0.49 \\
\hline
\end{tabular}

*P-values are calculated by comparing each group with the contributed control group

$* *$ Data is shown as median \pm standard deviation 


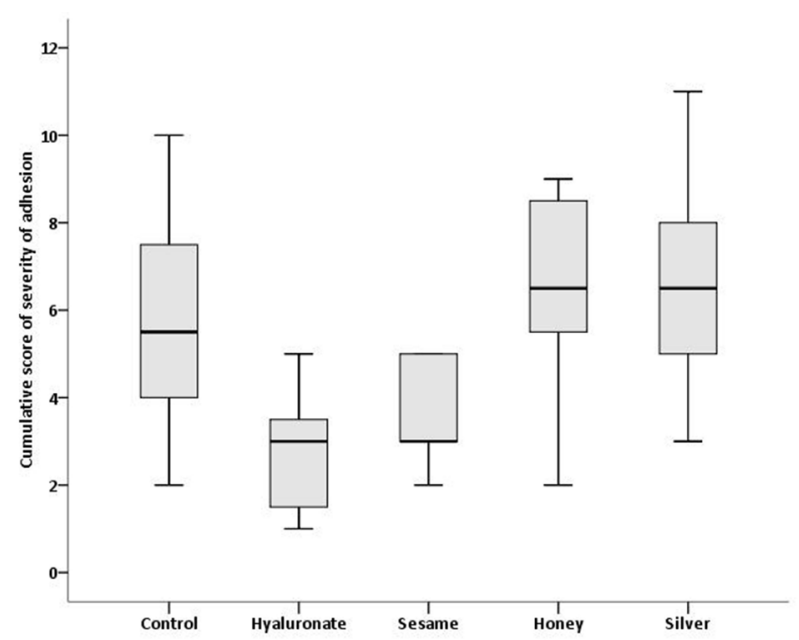

Figure $\mathbf{2}$ - The scores of severity of adhesions in each group based on the cumulative adhesion scoring scale.

\section{- Discussion}

Adhesion band formation occurs after surgical insult to peritoneum. The damage causes an inflammation with fibrinous exudate that is rich in fibrin which activates the coagulation cascade resulting in thrombin activation and more fibrin deposition. Accumulated fibrocollagenous tissue acts as a matrix for fibroblasts, which produce collagen and further stabilize the adhesion band. Endothelial and mesothelial cells and macrophages produce plasminogen activators, specifically tissue plasminogen activator which converts plasminogen to plasmin that is responsible for fibrin degradation. In the process of adhesion band formation plasminogen activator inhibitor-1 deactivates tissue plasminogen activator ${ }^{16}$. Considering this mechanisms efforts has been made to break this chain of causality for preventing postoperative surgical adhesion formation.

In our study sodium hyaluronate and sesame oil appeared to be the most effective in preventing postoperative surgical adhesion. The effect of hyaluronate on postoperative surgical adhesion has been investigated before ${ }^{17-20}$, all data suggest its role as an antiadhesive agent but none have used our method of adhesion induction, drug treatment and adhesion band evaluation to show its efficacy. In our study design we investigated the effect of hyaluronic acid as a "free floating" molecule therefore we injected $1 \mathrm{ml}$ of $10 \%$ sodium hyaluronate in peritoneal cavity. Thus, beside its direct barrier effect other properties as a signaling molecule is possible to be evaluated. Hyaluronic acid is a natural polysaccharide that can be found in most tissues and fluids of body. Several mechanisms have been suggested for its anti-adhesive properties. It can directly increase proliferation, migration and activation of mesothelial cells to injured area ${ }^{21}$. A possible receptor for hyaluronic acid-mesothelial interaction is cluster of differentiation $44^{22}$. Hyaluronic acid also may influence the mesothelial fibrinolytic capacity in response to monocyte-macrophage system and tumor necrosis factor alpha ${ }^{23,24}$. Our observation indicates that sodium hyaluronate may have a direct biological effect on peritoneum and may suggest that the pathophysiology of postoperative peritoneal repair can be modulated.

Sesame oil obtained from sesamum indicum is rich in polyunsaturated and monosaturated fatty acids, which also contains high amount of lignans such as sesamin, sesamol, sesamolin and sesaminol ${ }^{25}$. These agents have been found to exert antiinflammatory and anti-oxidative properties ${ }^{26-28}$. Specifically, sesamin has been found to halt proinflammatory cytokine production ${ }^{29}$. In our study we found that sesame oil may significantly reduce adhesion band formation in comparison to the control group based on Nair classification. Such result was not reproduced in cumulative 
adhesion scoring scale, which may be due to methods of evaluation of severity of adhesions band evaluation methods, study design and population. Grading adhesion bands according to Nair is a widely used method of adhesion band evaluation but it is rather weak in distinguishing lesser differences and distinction in highgrade adhesions. Cumulative adhesion scoring scale is quantitative, less reliable on observer and more sensitive, the reason is cumulative adhesion scoring scale avoids the problem of ranking events and; it only counts them to form a sum suitable for statistical analysis. Despite the earlier investigations for adhesion prevention property of honey ${ }^{30,31}$, we found no statistically significant results. This can be due to composition or physical characteristic of honey used in our study. Similarly, notwithstanding its anti-inflammatory and anti-microbial effect no significant result was seen in group received silver nanoparticles ${ }^{12,13}$.

\section{Conclusion}

Sodium hyaluronate and sesame oil may have a significant effect in preventing postoperative surgical adhesion formation. However, the latter showed inconsistent data and needs further research to elucidate its role.

\section{References}

1. Boland GM, Weigel RJ. Formation and prevention of postoperative abdominal adhesions. J Surg Res. 2006 May;132(1):312. PMID: 16457846.

2. Ergul E, Korukluoglu B. Peritoneal adhesions: facing the enemy. Int J Surg. 2008 Jun;6(3):253-60. PMID: 17617231.

3. Kossi J, Salminen P, Rantala A, Laato M. Population-based study of the surgical workload and economic impact of bowel obstruction caused by postoperative adhesions. Br J Surg. 2003 Nov;90(11):14414. PMID: 14598429.
4. Kirdak T, Uysal E, Korun N. Assessment of effectiveness of different doses of methylprednisolone on intraabdominal adhesion prevention. Ulus Travma Acil Cerrahi Derg. 2008 Jul;14(3):188-91. PMID: 18781413.

5. Topal E, Ozturk E, Sen G, Yerci O, Yilmazlar T. A comparison of three fibrinolytic agents in prevention of intra-abdominal adhesions. Acta Chir Belg. 2010 Jan-Feb;110(1):71-5. PMID: 20306914.

6. Turkcapar AG, Ozarslan C, Erdem E, Bumin C, Erverdi N, Kutlay J. The effectiveness of low molecular weight heparin on adhesion formation in experimental rat model. Int Surg. 1995 Jan-Mar;80(1):92-4. PMID: 7657504.

7. Ersoy E, Ozturk V, Yazgan A, Ozdogan M, Gundogdu H. Comparison of the two types of bioresorbable barriers to prevent intraabdominal adhesions in rats. J Gastrointest Surg. 2009 Feb;13(2):282-6. PMID: 18777122.

8. Aytan $\mathrm{H}$, Caliskan AC, Yener T, Demirturk F, Aytan P, Yenisehirli A. A novel antibiotic, linezolid, reduces intraperitoneal adhesion formation in the rat uterine horn model. Acta Obstet Gynecol Scand. 2009;88(7):7816. PMID: 19452326.

9. AhmadS, ElSherbiny NM, Jamal MS, Alzahrani FA, Haque R, Khan R, Zaidi SK, AlQhtani MH, Liou Gl, Bhatia K. Anti-inflammatory role of sesamin in STZ induced mice model of diabetic retinopathy. J Neuroimmunol. 2016 Jun 15;295-296:47-53. PMID: 27235348.

10. Narasimhulu CA, Selvarajan K, Burge KY, Litvinov D, Sengupta B, Parthasarathy S. Water-soluble components of sesame oil reduce inflammation and atherosclerosis. J Med Food. 2016 Jul;19(7):629-37. PMID: 27348418.

11. Osada DH, Minai M, Tsunoda I, Fujii T, Tsubata K, Satoh K. The effect of hyaluronic acid-carboxymethylcellulose in reducing adhesion reformation in rabbits. J Int Med Res. 1999;27(6):292-6. PMID: 10726238.

12.Duran N, Nakazato G, Seabra AB. Antimicrobial activity of biogenic silver nanoparticles, and silver chloride nanoparticles: an overview and comments. Appl Microbiol Biotechnol. 2016 Aug;100(15):6555-70. PMID: 27289481. 
13.Khan ST, Musarrat J, Al-Khedhairy AA. Countering drug resistance, infectious diseases, and sepsis using metal and metal oxides nanoparticles: current status. Colloids Surf B Biointerfaces. 2016 Oct 01;146:7083. PMID: 27259161.

14.Aziz Z, Abdul Rasool Hassan B. The effects of honey compared to silver sulfadiazine for the treatment of burns: A systematic review of randomized controlled trials. Burns. 2017 Feb;43(1):50-7. PMID: 27576926.

15.Farzadinia $P$, Jofreh $N$, Khatamsaz $S$, Movahed A, Akbarzadeh S, Mohammadi M, Barqahi A. Anti-inflammatory and Wound Healing Activities of Aloe vera, Honey and Milk Ointment on Second-Degree Burns in Rats. Int J Low Extrem Wounds. 2016 Sep;15(3):241-7. PMID: 27217089.

16. Hellebrekers BWJ, Kooistra T. Pathogenesis of postoperative adhesion formation. $\mathrm{Br} \mathrm{J}$ Surg. 2011;98(11):1503-16. doi: 10.1002/ bjs.7657.

17. Becker JM, Dayton MT, Fazio VW, Beck DE, Stryker SJ, Wexner SD, Wolff BG, Roberts PL, Smith LE, Swenney SA, Moore M. Prevention of postoperative abdominal adhesions by a sodium hyaluronate-based bioresorbable membrane: a prospective, randomized, double-blind multicenter study. J Am Coll Surg. 1996 Oct;183(4):297-306. PMID: 8843257.

18.Rodgers KE, Johns DB, Girgis W, Campeau J, diZerega GS. Reduction of adhesion formation with hyaluronic acid after peritoneal surgery in rabbits. Fertil Steril. 1997 Mar;67(3):553-8. PMID: 9091346.

19.Rodgers KE, Johns DB, Girgis W, diZerega GS. Prevention of adhesion formation with intraperitoneal administration of tolmetin and hyaluronic acid. J Invest Surg. 1997 NovDec;10(6):367-73. PMID: 9654393.

20.Sawada T, Hasegawa K, Tsukada K, Kawakami $\mathrm{S}$. Adhesion preventive effect of hyaluronic acid after intraperitoneal surgery in mice. Hum Reprod. 1999 Jun;14(6):1470-2. PMID: 10357961.

21.Reijnen MMPJ, Falk $P$, van Goor $H$, Holmdahl $L$. The antiadhesive agent sodium hyaluronate increases the proliferation rate of human peritoneal mesothelial cells. Fertil Steril.74(1):146-51. PMID: 10899512.
22.Culty M MK, Kincade PW, Sikorski E, Butcher $\mathrm{EC}$, Underhill $\mathrm{C}$. The hyaluronate receptor is a member of the CD44 (H-CAM) family of cell surface glycoproteins. J Cell Biol. 1990;111(6):2765-74. PMID: 2116369.

23.Sikkink CJ, Reijnen MM, Falk P, van Goor $\mathrm{H}$, Holmdahl L. Influence of monocyte-like cells on the fibrinolytic activity of peritoneal mesothelial cells and the effect of sodium hyaluronate. Fertil Steril. 2005 Oct;84 Suppl 2:1072-7. PMID: 16209995.

24.Reijnen MJ, van Goor H, Falk P, Hedgren M, Holmdahl L. Sodium hyaluronate increases the fibrinolytic response of human peritoneal mesothelial cells exposed to tumor necrosis factor $\alpha$. Arch Surg. 2001;136(3):291-6. PMID: 11231848.

25. Moazzami AA, Haese SL, Kamal-Eldin A. Lignan contents in sesame seeds and products. Eur J Lipid Sci Technol. 2007;109(10):1022-7.

26. Narasimhulu CA, Selvarajan K, Litvinov D, Parthasarathy S. Anti-atherosclerotic and anti-inflammatory actions of sesame oil. J Med Food. 2015 Jan;18(1):11-20. PMID: 25562618.

27.Yashaswini PS, Sadashivaiah B, Ramaprasad TR, Singh SA. In vivo modulation of LPS induced leukotrienes generation and oxidative stress by sesame lignans. J Nutr Biochem. 2017 Mar;41:151-7. PMID: 28095362.

28.Gouveia Lde A, Cardoso CA, de Oliveira GM, Rosa G, Moreira AS. Effects of the intake of sesame seeds (Sesamum indicum L.) and derivatives on oxidative stress: a systematic review. J Med Food. 2016 Apr;19(4):337-45. PMID: 27074618.

29.Jeng KC, Hou RC, Wang JC, Ping LI. Sesamin inhibits lipopolysaccharide-induced cytokine production by suppression of p38 mitogen-activated protein kinase and nuclear factor-kappaB. Immunol Lett. 2005 Feb 15;97(1):101-6. PMID: 15626481.

30.Emre A, Akin M, Isikgonul I, Yuksel O, Anadol $A Z$, Cifter C. Comparison of intraperitoneal honey and sodium hyaluronatecarboxymethylcellulose (Seprafilm) for the prevention of postoperative intraabdominal adhesions. Clinics (Sao Paulo). 2009;64(4):363-8. PMID: 19488596. 
31.Yuzbasioglu MF, Kurutas EB, Bulbuloglu E, Goksu M, Atli Y, Bakan V, Kale IT. Administration of honey to prevent peritoneal adhesions in a rat peritonitis model. Int J Surg. 2009 Feb; 7(1):54-7. PMID: 19042166.

\section{Correspondence:}

Seyed Mohammad Reza Javadi

Shahid Beheshti Boulevard, Besat Hospital

General Surgery Department, Hamadan, Iran

Phone: +988132640020

smrezajavadi@gmail.com

Received: Apr 19, 2017

Review: June 20, 2017

Accepted: July 18, 2017
Conflict of interest: none

Financial source: none
${ }^{1}$ Research performed at General Surgery Department, Besat Hospital, Medical Sciences, Hamadan University, Iran.

